\title{
Effect of systematic downsizing rigid ring annuloplasty in patients with moderate ischemic mitral regurgitation
}

\author{
Denis Bouchard, MD, ${ }^{\mathrm{a}}$ Henrik Jensen, MD, ${ }^{\mathrm{a}}$ Michel Carrier, MD, ${ }^{\mathrm{a}}$ Philippe Demers, MD, ${ }^{\mathrm{a}}$ \\ Michel Pellerin, MD, ${ }^{a}$ Louis P. Perrault, MD, PhD, ${ }^{a}$ and Jean Lambert, $\mathrm{PhD}^{\mathrm{b}}$
}

\begin{abstract}
Objective: Functional ischemic mitral regurgitation (FIMR) increases mortality independently of the baseline characteristics and ventricular function. The effect of treating FIMR with annuloplasty is unclear when mitral regurgitation is moderate. Myocardial revascularization alone has been shown to improve mitral valve function.

Methods: We randomized 31 patients with moderate (grade 2-4) FIMR to receive either coronary artery bypass grafting (CABG) alone or CABG plus downsizing mitral ring annuloplasty. The patients were followed up for clinical outcomes and echocardiographic assessment of mitral valve function and left ventricular dimensions at 3 and 12 months. Clinical improvement was assessed using the Minnesota quality-of-life questionnaire, 6-minute walk test, and brain natriuretic peptide levels.
\end{abstract}

Results: The clinical course was similar in the 2 groups of patients during the study period. FIMR was perfectly corrected intraoperatively in the ring group. Echocardiographic follow-up at 3 months showed no difference in the FIMR grade between the 2 groups (66\% less than grade 2 in the CABG alone and $86 \%$ in the CABG plus ring group; $P=.316$ ). The improvement in the CABG alone group was even more marked at 12 months ( $85 \%$ less than grade 2 in the $\mathrm{CABG}$ group and $85 \%$ in the $\mathrm{CABG}$ plus ring group). The left ventricular ejection fraction was significantly better at 3 months in the CABG alone group, although at 12 months, the left ventricular ejection fraction in the 2 groups had improved similarly.

Conclusions: Although initially effective at reducing moderate FIMR, the addition of a ring did not change the clinical course after CABG surgery. At 12 months, no echocardiographic difference was found in terms of residual mitral regurgitation, left ventricular dimensions and function, or clinical outcomes. (J Thorac Cardiovasc Surg 2014;147:1471-7)

Earn CME credits at

http://jtcvs.com/cme/home

Functional ischemic mitral regurgitation (FIMR) increases mortality independently of the baseline characteristics and ventricular function and is directly related to the degree of FIMR. ${ }^{1}$ Many surgeons address FIMR at surgical revascularization, because some clinical studies have not supported coronary artery bypass grafting $(\mathrm{CABG})$ as an effective treatment of FIMR. ${ }^{2}$ Downsizing ring annuloplasty (ring) as an adjunct procedure to CABG has been used to correct Carpentier type I and type IIIB dysfunction in patients with FIMR, with a high freedom rate from intraoperative mitral regurgitation, although it can recur with time. Some

\footnotetext{
From the Department of Cardiac Surgery, ${ }^{\text {a }}$ Montreal Heart Institute and Université de Montréal; and the Department of Social and Preventive Medicine, ${ }^{\mathrm{b}}$ Université de Montréal, Montreal, Quebec, Canada.

This study was supported by a Montreal Heart Institute clinical research grant Disclosures: Authors have nothing to disclose with regard to commercial support. Received for publication Dec 13, 2012; revisions received Jan 29, 2013; accepted for publication May 23, 2013; available ahead of print July 15, 2013.

Address for reprints: Denis Bouchard, MD, Department of Cardiac Surgery, Montreal

Heart Institute, 5000 Belanger St, Montreal, QC H1T 1C8, Canada (E-mail: Denis.

Bouchard@icm-mhi.org).

$0022-5223 / \$ 36.00$

Copyright (c) 2014 by The American Association for Thoracic Surgery

http://dx.doi.org/10.1016/j.jtcvs.2013.05.024
}

investigators have reported excellent long-term results, ${ }^{3,4}$ although others have reported an exponentially increasing rate of recurrent FIMR up to approximately $70 \%$ at 5 years. $^{4-6}$ The effect of adding downsizing ring annuloplasty to CABG in patients with ischemic mitral regurgitation has been thoroughly addressed in published studies. A recent meta-analysis of a nonrandomized series ${ }^{7}$ and 2 randomized studies ${ }^{8,9}$ comparing $\mathrm{CABG}$ and $\mathrm{CABG}$ combined with downsizing ring annuloplasty showed that the addition of a ring resulted in a lower mitral regurgitation grade and New York Heart Association (NYHA) class compared with CABG alone but did not improve the survival rate. The present study reports the results of a randomized trial focusing on the clinical and echocardiographic outcomes throughout 1 year after surgery.

\section{METHODS}

\section{Study Population}

From 2002 to 2008, 67 patients with coronary artery disease and FIMR were referred for cardiac surgery at the Montreal Heart Institute and were screened for randomization. The inclusion criteria were grade $2+$ FIMR with a concomitant need for CABG. The exclusion criteria were papillary muscle rupture, a concomitant need for aortic valve surgery, life expectancy less than 12 months from noncardiac causes, creatinine $>200$ $\mu \mathrm{mol} / \mathrm{L}$, and more than grade 2 FIMR. A total of 31 patients were included in the study and randomized to CABG alone $(n=16)$ or CABG combined with ring annuloplasty $(n=15)$. All the patients provided written informed 


$$
\begin{aligned}
& \text { Abbreviations and Acronyms } \\
& \begin{aligned}
\text { BNP } & =\text { brain natriuretic peptide } \\
\text { CABG } & =\text { coronary artery bypass grafting } \\
\text { ERO } & =\text { effective regurgitation orifice } \\
\text { FIMR } & =\text { functional ischemic mitral regurgitation } \\
\text { QOL } & =\text { quality of life } \\
\text { LA } & =\text { left atrial } \\
\text { LV } & =\text { left ventricular } \\
\text { LVEF } & =\text { LV ejection fraction } \\
\text { MR } & =\text { mitral regurgitation } \\
\text { NYHA } & =\text { New York Heart Association } \\
\text { OR } & =\text { operating room }
\end{aligned}
\end{aligned}
$$

consent, and the local ethics committee approved the study. All authors had full access to, and take full responsibility for, the integrity of the data.

\section{Operative Technique}

All surgical procedures were performed through a midline sternotomy. Mild hypothermic cardiopulmonary bypass and cold blood cardioplegia were used. The left internal mammary artery was grafted to the left anterior descending coronary artery in all patients. The remaining revascularization was done using saphenous vein grafts. In the CABG group, 2 patients underwent surgery with an off-pump beating heart technique. In the CABG plus ring group, rigid ring annuloplasty was performed (size 26-28), downsized by 2 sizes according to the anterior leaflet height and intercommissural distance. Three patients received a Carpentier Edwards ETlogix ring (Edwards Lifesciences, Irvine, Calif), and 12 patients received a Carbomedics Annuloflo ring (Sorin, Milano, Italy).

\section{Echocardiography}

Serial transthoracic echocardiographic studies were performed pre-, intra, and postoperatively at 3 and 12 months. The left ventricular (LV) M-mode spectrum was obtained in the parasternal long-axis view; the LV dimensions at both end cardiac diastole (LVDd) and systole (LVDs) were measured. LV fractional shortening was calculated as (LVDd - LVDs)/LVDd $\times 100 \%$. Apical 4-chamber and 2-chamber views were recorded. The Simpson method was used to calculate the end-systolic and end-diastolic LV volumes (LVVd, LVVs). The LV ejection fraction (LVEF) was calculated as (LVVd LVVs) $/ L V V d \times 100 \%$. Mitral regurgitation $(M R)$ was quantified by measurements of the MR jet area and left atrial (LA) area using color mapping of the apical 4-chamber view during cardiac systole. MR was semiquantitatively graded using the jet area/LA area $\times 100 \%$, with grade I representing $<20 \%$; grade II, $20-40 \%$; and grade III-IV, $\geq 40 \%$. The effective regurgitation orifice (ERO) area, MR volume, and regurgitation fraction were calculated using the proximal isovelocity surface area or Doppler method, as previously described. ${ }^{10,11}$ MR was further quantitatively graded as I, II, III, IV, with an ERO of $<20,20-29,30-39$, and $\geq 40 \mathrm{~mm}^{2}$, regurgitant volume of $<30,30-44,45-59$, and $\geq 60 \mathrm{~mL}$, and regurgitation fraction of $<30,30-39,40-49$, and $\geq 50 \%$, respectively.

\section{Clinical Follow-up}

The patients completed the Minnesota quality of life (QOL) questionnaire ${ }^{12}$ at 3 months. The French version of this questionnaire was tested for validity and reliability. ${ }^{13}$ Cronbach's alpha ranged from 0.73 to 0.93 , except for its incapacity dimension (0.40). The intraclass correlation coefficients were all greater than 0.70 in the 4 dimensions of the questionnaire. These results were similar to those obtained with the original questionnaire. ${ }^{12}$ The patients also performed a 6-minute walk test and underwent brain natriuretic peptide (BNP) measurements. BNP measurements were taken and the QOL questionnaire was completed preoperatively and at the 3- and 12-month follow-up examinations conducted by physicians at the Montreal Heart Institute Valve Clinic.

\section{Study Endpoints}

The primary endpoint was the LV dimension changes at 1 year. The secondary endpoints were difference in the BNP levels, QOL score, and 6-minute walk test results at 3 months, and the NYHA class and MR grade at 3 months and 1 year.

The randomization took place in the operating room (OR), after the skin incision. The patients were unaware of the mitral correction status for the first year after their surgery. The surgeons and cardiology teams treating the patient and the echocardiographers analyzing the images were aware of the correction status.

\section{Statistical Analysis}

Continuous data are presented as the mean \pm standard deviation, and the categorical data are presented as numbers (percentages).

Between the groups, comparisons were performed using Student $t$ tests and Pearson's chi-square tests for continuous and categorical variables, respectively. For continuous variables with preoperative measures, the postoperative values were compared between groups using analyses of covariance to reduce the error mean squares.

Within group comparisons were performed using paired $t$ tests and the McNemar-Bowker chi-square test for continuous and categorical variables, respectively.

Usual assumptions such as normality and homoscedasticity of the variance were verified. Transformations and/or more robust procedures such as nonparametric tests were used when necessary. Parallelism of the regression lines (or interaction) was verified when using analyses of covariance, but no interaction was detected. The level of significance was set at .05 for all procedures. Because of the small sample sizes, adjustments for multiplicity of testing were not used. All analyses were performed using the Statistical Package for Social Sciences, version 20 (SPSS, Inc, Chicago, Ill).

\section{RESULTS}

\section{Patient Population and Perioperative Outcomes}

Table 1 lists the baseline characteristics of the 2 groups, and the operative procedure details are listed in Table 2 . No significant difference was found in the preoperative patient characteristics between the 2 groups. As expected, the group randomized to $\mathrm{CABG}$ plus ring had longer crossclamp and cardiopulmonary bypass times.

\section{Clinical Follow-up}

Postoperative versus preoperative. The clinical followup data are listed in Table 3. In both groups, the NYHA class had improved at 3 and at 12 months compared with preoperatively. The percentage of patients in NYHA class III and IV decreased from $50 \%$ at the preoperative evaluation to $17 \%$ and $0 \%$ at 3 and 12 months, respectively, for the CABG group and from $40 \%$ preoperatively to $0 \%$ and $8 \%$ for the CABG plus ring group. However, owing to small samples, these important decreases were not statistically analyzable using the McNemar-Bowker chi-square test.

No statistically significant improvement in QOL was observed at 3 months of follow-up in either group (CABG, $P=.276$; CABG plus ring, $P=.131$ ). A trend was seen toward a reduction in BNP at 3 months in the 
TABLE 1. Patient characteristics

\begin{tabular}{lccc}
\hline \multicolumn{1}{c}{ Characteristic } & $\begin{array}{c}\text { CABG } \\
(\mathbf{n}=\mathbf{1 6})\end{array}$ & $\begin{array}{c}\text { CABG plus } \\
\text { ring }(\mathbf{n}=\mathbf{1 5})\end{array}$ & $\boldsymbol{P}$ value \\
\hline Male gender & $14(88)$ & $12(75)$ & .585 \\
Smoking (yes) & $5(31)$ & $5(33)$ & .905 \\
Diabetes (yes) & $8(50)$ & $4(27)$ & .195 \\
Dyslipidemia (yes) & $12(75)$ & $10(67)$ & .624 \\
Hypertension (yes) & $9(56)$ & $11(73)$ & .337 \\
COPD (yes) & $3(19)$ & $4(27)$ & .613 \\
Preoperative atrial fibrillation & $2(13)$ & $3(20)$ & .570 \\
Previous AMI (yes) & $12(75)$ & $9(60)$ & .389 \\
Creatinine $(\mu$ mol/L) & $93 \pm 28$ & $105 \pm 24$ & .231 \\
Age $(y)$ & $65 \pm 12$ & $69 \pm 7$ & .290 \\
BMI $\left(\mathrm{kg} / \mathrm{m}^{2}\right)$ & $27 \pm 4$ & $27 \pm 5$ & .942 \\
\hline
\end{tabular}

Data are presented as $\mathrm{n}(\%)$ or mean \pm standard deviation. $C A B G$, Coronary artery bypass grafting; ring, downsizing mitral ring annuloplasty; $C O P D$, chronic obstructive pulmonary disease; $A M I$, acute myocardial infarction; $B M I$, body mass index.

CABG plus ring patients $(P=.065)$ that was not present in the CABG patients $(P=.317)$.

CABG versus CABG plus ring. In the CABG group, 1 patient died at 2 months postoperatively, but no new deaths had occurred at 1 year. In the CABG plus ring group, 1 patient died on postoperative day 1 of bleeding and tamponade, with no deaths afterward. All patients were in sinus rhythm preoperatively and at 3 and 12 months of follow-up. One patient in the CABG plus ring group required an implantable automatic cardioverter defibrillator preoperatively; no other pacemakers were implanted postoperatively. A significant difference was seen in the NYHA class at 3 months $(P=.052)$, with more CABG-only patients returning to NYHA class I (Table 3 ). At 1 year, this difference had decreased to a nonsignificant level $(P=.122)$. The changes in NYHA class from preoperatively to 3 months, from preoperatively to 12 months, and from 3 months to 12 months were compared between the 2 groups (Table 3 ). The Canadian Cardiovascular Society classes were similar at 3 and 12 months $(P=.651$ at 3 and 12 months). The 6-minute walk test results at 3 months were similar $(P=.415)$. The Minnesota QOL score and BNP blood level were also similar at 3 months $(P=.490$ and $P=.766$, respectively). One early stroke occurred in the ring group and none in the CABG-only group. One readmission was

TABLE 2. Perioperative characteristics

\begin{tabular}{lccc}
\hline \multicolumn{1}{c}{ CABG } & CABG plus & \\
\hline LIMA to LAD & $(\mathbf{n}=\mathbf{1 6})$ & ring $(\mathbf{n}=\mathbf{1 5})$ & $\boldsymbol{P}$ value \\
Clamp time (min) & $63 \pm 29$ & $15(100)$ & 1.000 \\
ECC (min) & $89 \pm 31$ & $94 \pm 28$ & .008 \\
CK-MB day 1 (IU/L) & $21 \pm 30$ & $24 \pm 10 \pm 37$ & .046 \\
\hline Data are presented as n (\%) & or mean \pm standard deviation. LIMA, Left internal \\
mammary artery; $L A D$, left anterior descending coronary artery; $E C C$, extracorporeal \\
circulation; $C K M B$, creatine kinase-myocardial band isoenzyme; CABG, coronary \\
artery bypass grafting; ring, downsizing mitral ring annuloplasty.
\end{tabular}

necessary in each group at 1 year. The need for oral warfarin therapy was similar in the 2 groups $(P=.116)$.

\section{Echocardiographic Results}

Postoperatively versus preoperatively. The MR grades measured intraoperatively and at 3 and 12 months of follow-up are listed in Table 4. In the CABG plus ring group, the intraoperative results were near-perfect, with $93 \%$ having MR grade 0 . At 3 months, some grade II MR had appeared $(14 \%)$, with a significant number of patients in grade I $(43 \%)$. The echocardiographic grades were slightly greater at 1 year, with $7 \%$ in grade II and III. In the CABG-only group, the pattern of MR differed, with most patients still having grade II MR intraoperatively, decreasing to grade I or less in $66 \%$ by 3 months and $85 \%$ at 1 year. Considering the echocardiographic results at 3 and 12 months of follow-up more precisely, in both groups, the MR parameters and LV dimensions showed an overall pattern of reduction compared with preoperatively (Table 5). Specifically, for the CABG group, a significant reduction was seen in the ERO, jet area, jet area/LA area, regurgitant volume, regurgitant fraction, LV end-diastolic diameter, and LV end-systolic diameter at 3 and 12 months. Furthermore in the CABG group, fractional shortening had improved significantly at 3 months, and the LVEF had done so at 12 months. For the CABG plus ring group, a similar decrease in the ERO, jet area, jet area/LA area, regurgitant volume, and regurgitant fraction was noted. However, no significant improvements were noted in the repair group regarding the LV dimensions and volumes or fractional shortening and LVEF at the 2 follow-up points.

CABG versus CABG plus ring. No preoperative significant differences were found in the various echocardiographic measurements.

Immediately after surgery, the residual MR was markedly less in the ring group ( $93 \%$ with no MR at all) compared with the CABG-only group, in which only $13 \%$ had improved to grade I $(P=.000$; Table 4$)$. This difference was no longer significant at $3(P=.25)$ or 12 $(P=.72)$ months. To better understand how the MR grade changed at the different echocardiographic examinations between the 2 groups, we compared the difference in MR grade at the 3 measurement points. The changes occurring between the day of surgery (DOS) transesophageal echocardiogram and the 3-month echocardiogram, between the DOS and 12-month echocardiograms, and the 3-month and 12-month echocardiograms were compared (Table 6). For the DOS-3-month comparison, $67 \%$ of the CABG group had improved by 1 or 2 grades, $22 \%$ remained identical, and $11 \%$ had worsened. In the CABG plus ring group, no patient had improved their MR grade (the surgical procedure completely corrected the MR in the OR room), although $54 \%$ had some recurrence and the MR had worsened by 1 or 2 grades $(P=.016)$. 
TABLE 3. Clinical follow-up

\begin{tabular}{|c|c|c|c|c|c|c|}
\hline \multirow[b]{2}{*}{ Variable } & \multicolumn{2}{|c|}{ Preoperative } & \multicolumn{2}{|c|}{$3 \mathrm{mo}$} & \multicolumn{2}{|r|}{$1 \mathbf{y}$} \\
\hline & CABG & CABG plus ring & CABG & CABG plus ring & CABG & CABG plus ring \\
\hline Deaths (n) & 0 & 0 & $1(6)$ & $1(7)$ & 0 & 0 \\
\hline \multicolumn{7}{|l|}{ NYHA class $(\%)$} \\
\hline I & 10 & 0 & 75 & 46 & 100 & 77 \\
\hline II & 40 & 60 & 8 & 54 & 0 & 15 \\
\hline III-IV & 50 & 40 & 17 & 0 & 0 & 8 \\
\hline \multicolumn{7}{|l|}{ CCS class } \\
\hline $0-\mathrm{I}$ & & & 100 & 92 & 100 & 100 \\
\hline II-IV & & & 0 & 8 & 0 & 0 \\
\hline Stroke & & & $0(0)$ & $1(8)$ & $0(0)$ & $0(0)$ \\
\hline Cardiac hospitalization & & & & & $1(11)$ & $1(8)$ \\
\hline OAT & & & & & $1(11)$ & $5(38)$ \\
\hline 6-min Walk test (m) & & & $409 \pm 90$ & $383 \pm 63$ & & \\
\hline QOL score & $28 \pm 26$ & $33 \pm 25$ & $15 \pm 12$ & $19 \pm 15$ & & \\
\hline $\mathrm{BNP}(\mathrm{pg} / \mathrm{mL})$ & $1911 \pm 3174$ & $1743 \pm 1361$ & $926 \pm 951$ & $671 \pm 670$ & & \\
\hline
\end{tabular}

Data are presented as n (\%), percentages, or mean \pm standard deviation. NYHA, New York Heart Association; CCS, Canadian Cardiovascular Society; OAT, oral anticoagulation therapy; $Q O L$, Minnesota quality of life questionnaire; $B N P$, brain natriuretic peptide; $C A B G$, coronary artery bypass grafting; ring, downsizing mitral ring annuloplasty.

The phenomenon was even more marked when comparing the OR echocardiographic values to those at 12 months. In the CABG group, the MR grade had improved in $77 \%$, was stable in $15 \%$, and had worsened in $8 \%$. In the CABG plus ring patients, the MR grade had worsened in $69 \%(P=.004)$. The differences in the echocardiographic changes from 3 to 12 months were not statistically significant between the 2 groups $(P=.13)$.

All continuous echocardiographic parameters were compared at 3 and 12 months, adjusting for the preoperative values. The 3- and 12-month adjusted values are listed on Table 7 . The only statistically significant difference was better LVEF at 3 months in the CABG-only group: $49 \%$ $\pm 3 \%$ for the CABG group compared with $42 \% \pm 2 \%$ for the CABG plus ring group $(P=.045)$. This difference had disappeared at 1 year, and in both groups the LVEF had improved to comparable levels (CABG 52\% $\pm 2 \%$ and CABG plus ring $48 \% \pm 2 \% ;(P=.204))$.

\section{DISCUSSION}

A total of 31 patients with moderate ischemic MR were randomized to $\mathrm{CABG}$ alone or $\mathrm{CABG}$ plus a downsized mitral ring. The major findings of the present study were, first, that combining a downsized mitral annuloplasty ring with CABG successfully eliminated MR immediately in the OR, although $\mathrm{CABG}$ alone did not. Second, at 3 and 12 months of follow-up, no significant difference was found in the residual MR grade between the 2 groups. At the 3-month echocardiogram, the MR had started improving in the CABG-only group (with $44 \%$ of patients improving by 1 and $22 \%$ by 2 grades). During the same period, the patients in the CABG plus ring group had developed recurrent MR by 1 grade in $46 \%$ and 2 grades in $8 \%$. This phenomenon of delayed improvement after CABG and delayed recurrence after annuloplasty was even more evident on the 12-month echocardiogram. Third, the ERO, jet area, jet area/LA area, regurgitant volume, and regurgitant fraction were all decreased by the same magnitude 1 year after surgery, with no better results conferred by the presence of the restrictive annuloplasty. Similarly, the LV systolic and diastolic dimensions were improved in both groups, with no intergroup difference found. Finally, although for the CABG group, fractional shortening showed some early improvement at 3 months $(P=.060)$ and the LVEF had improved significantly at 12 months $(P=.040)$, no improvement was seen in the contractile function of the left ventricle in the CABG plus ring group. When performing group comparisons adjusted for the preoperative level, the LVEF was significantly better at 3 months in the CABG-only group. Adaptation to the

TABLE 4. Mitral regurgitation grade preoperatively, intraoperatively, and 3 months and 1 year postoperatively

\begin{tabular}{|c|c|c|c|c|c|c|c|c|}
\hline \multirow[b]{2}{*}{ MR grade } & \multicolumn{2}{|c|}{ Preoperatively (\%) } & \multicolumn{2}{|c|}{ Intraoperatively $(\%)$} & \multicolumn{2}{|c|}{$3 \mathrm{mo}(\%)$} & \multicolumn{2}{|c|}{$12 \mathrm{mo}(\%)$} \\
\hline & $\begin{array}{c}\text { CABG } \\
(n=16)\end{array}$ & $\begin{array}{c}\text { CABG plus } \\
\text { ring }(n=15)\end{array}$ & $\begin{array}{c}\text { CABG } \\
(n=16)\end{array}$ & $\begin{array}{c}\text { CABG plus } \\
\text { ring }(n=15)\end{array}$ & $\begin{array}{c}\text { CABG } \\
(n=14)\end{array}$ & $\begin{array}{c}\text { CABG plus } \\
\text { ring }(n=14)\end{array}$ & $\begin{array}{c}\text { CABG } \\
(n=14)\end{array}$ & $\begin{array}{c}\text { CABG plus } \\
\text { ring }(n=13)\end{array}$ \\
\hline 0 & 0 & 0 & 0 & 93 & 22 & 43 & 21 & 23 \\
\hline 1 & 0 & 0 & 13 & 7 & 44 & 43 & 64 & 62 \\
\hline 2 & 100 & 100 & 87 & 0 & 33 & 14 & 14 & 7 \\
\hline 3 & 0 & 0 & 0 & 0 & 0 & 0 & 0 & 7 \\
\hline
\end{tabular}

$M R$, Mitral regurgitation; $C A B G$, coronary artery bypass grafting; ring, downsizing mitral ring annuloplasty. 
TABLE 5. Echocardiographic parameters preoperatively and 3 and 12 months postoperatively and comparisons within each group

\begin{tabular}{|c|c|c|c|c|c|c|}
\hline \multirow[b]{2}{*}{ Variable } & \multicolumn{2}{|c|}{ Preoperatively } & \multicolumn{2}{|c|}{$3 \mathrm{mo}$} & \multicolumn{2}{|c|}{$12 \mathrm{mo}$} \\
\hline & $\begin{array}{c}\text { CABG } \\
(n=16)\end{array}$ & $\begin{array}{c}\text { CABG plus } \\
\operatorname{ring}(n=15)\end{array}$ & $\begin{array}{c}\text { CABG } \\
(n=14)\end{array}$ & $\begin{array}{c}\text { CABG plus } \\
\text { ring }(n=14)\end{array}$ & $\begin{array}{c}\text { CABG } \\
(n=14)\end{array}$ & $\begin{array}{c}\text { CABG plus } \\
\text { ring }(n=13)\end{array}$ \\
\hline $\mathrm{ERO}\left(\mathrm{mm}^{2}\right)$ & $22.7 \pm 5.2$ & $19.5 \pm 3.2$ & $6.7 \pm 7.6(.004)$ & $5.9 \pm 7.6(.020)$ & $4.5 \pm 7.2(.000)$ & $8.9 \pm 11.2(.277)$ \\
\hline Jet area $\left(\mathrm{cm}^{2}\right)$ & $7.5 \pm 4.0$ & $7.8 \pm 3.4$ & $4.1 \pm 3.8(.006)$ & $3.7 \pm 4.3(.027)$ & $3.4 \pm 3.8(.013)$ & $3.8 \pm 3.3(.002)$ \\
\hline LA area $\left(\mathrm{cm}^{2}\right)$ & $21.1 \pm 7.2$ & $19.9 \pm 7.2$ & $23.8 \pm 8.4(.391)$ & $21.1 \pm 8.7(.115)$ & $18.7 \pm 10.0(.248)$ & $22.2 \pm 5.7(.895)$ \\
\hline Jet area/LA area $(\%)$ & $34.1 \pm 7.0$ & $39.0 \pm 5.9$ & $15.8 \pm 11.4(.002)$ & $16.5 \pm 16.1(.008)$ & $16.6 \pm 12.6(.008)$ & $16.4 \pm 13.5(.012)$ \\
\hline $\mathrm{RV}(\mathrm{mL})$ & $36.9 \pm 8.6$ & $35.0 \pm 10.7$ & $10.6 \pm 11.7(.000)$ & $12.0 \pm 15.3(.005)$ & $6.7 \pm 9.8(.000)$ & $13.5 \pm 16.9(.060)$ \\
\hline $\mathrm{RF}(\%)$ & $21.9 \pm 10.0$ & $25.0 \pm 11.7$ & $7.0 \pm 8.1(.010)$ & $9.1 \pm 10.1(.019)$ & $4.0 \pm 5.5(.008)$ & $8.1 \pm 10.4(.168)$ \\
\hline LVEDD $(\mathrm{cm})$ & $5.9 \pm 0.8$ & $5.4 \pm 0.7$ & $5.6 \pm 0.7(.050)$ & $5.1 \pm 0.9(.149)$ & $5.5 \pm 0.7(.003)$ & $5.3 \pm 0.7(.339)$ \\
\hline LVESD (cm) & $4.4 \pm 0.9$ & $4.0 \pm 0.8$ & $3.8 \pm 1.0(.012)$ & $3.8 \pm 1.0(.763)$ & $3.9 \pm 1.0(.057)$ & $3.8 \pm 1.0(.344)$ \\
\hline LVEDV (mL) & $118.4 \pm 40.3$ & $133.9 \pm 35.1$ & $97.2 \pm 31.5(.129)$ & $104.4 \pm 31.9(.076)$ & $118.8 \pm 52.2(.050)$ & $119.2 \pm 48.9(.071)$ \\
\hline LVESV (mL) & $57.4 \pm 30.2$ & $76.6 \pm 30.1$ & $38.6 \pm 9.6(.159)$ & $53.6 \pm 23.4(.066)$ & $58.4 \pm 41.2(.224)$ & $62.0 \pm 30.2(.066)$ \\
\hline FS $(\%)$ & $25.7 \pm 10.7$ & $28.6 \pm 10.6$ & $32.1 \pm 12.0(.060)$ & $28.3 \pm 13.3(.914)$ & $29.2 \pm 9.1(.333)$ & $30.4 \pm 9.7(.918)$ \\
\hline LVEF $(\%)$ & $41.5 \pm 17.4$ & $45.7 \pm 11.4$ & $45.8 \pm 20.2(.112)$ & $43.3 \pm 12.9(.237)$ & $51.4 \pm 13.3(.040)$ & $48.4 \pm 6.7(.181)$ \\
\hline
\end{tabular}

Data are presented as mean \pm standard deviation, with $P$ values in parentheses $(P$ values represent $\mathrm{t}$ test comparison for preoperatively versus postoperatively). ERO, Effective orifice area; $L A$, left atrium; $R V$, regurgitant volume; $R F$, regurgitant fraction; $L V E D D$, left ventricular end-diastolic diameter; $L V E S D$, left ventricular end-systolic diameter; $L V E D V$, left ventricular end-diastolic volume; $L V E S V$, left ventricular end-systolic volume; $F S$, fractional shortening; $L V E F$, left ventricular ejection fraction; $C A B G$, coronary artery bypass grafting; ring, downsizing mitral ring annuloplasty.

increased in afterload after the return of mitral valve competency could explain the absence of LVEF improvement after annuloplasty. As the ventricle adapts and the volume overload recedes, LV function will start to improve by 1 year. ${ }^{14}$ The effect of adding mitral annuloplasty to CABG was assessed using important clinical parameters, such as NYHA class, Canadian Cardiovascular Society class, BNP level, and QOL scores. The NYHA functional class improved in both groups; however, this clinical improvement was statistically more important for the CABG-only group at 3 months, a possible consequence of the observed decline in LVEF in the CABG plus ring patients at the same point. At 1 year, both groups had improved their NYHA class and LVEF equally. The heart failure status was also assessed using the Minnesota QOL score and BNP measurements. These assessments were not discriminatory of better improvement with either operative strategy. The addition of downsized ring annuloplasty to CABG only transiently reduced the MR, and, at 3 months, the patients with the annuloplasty ring seemed to do worse than the patients with CABG alone. Their LV function was depressed and their functional class improvement lagged behind that of the CABG-only group. By 1 year, the functional improvements and echocardiographic values regarding LV function and mitral valve function were identical.
The comparison of $\mathrm{CABG}$ with and without mitral valve surgery was assessed by a meta-analysis of 9 retrospective studies, including a total of 2479 patients with FIMR grade 2.2 to 3.9 undergoing CABG $(\mathrm{n}=1515)$ or $\mathrm{CABG}$ combined with mitral valve surgery $(\mathrm{n}=964){ }^{7}$ In that study, no benefit for long-term survival was observed; however, mitral valve surgery did reduce the MR grade more than did CABG-only surgery. NYHA class improvement could not be demonstrated statistically in this large meta-analysis. In 2009, Fattouch et $\mathrm{al}^{8}$ published the first randomized study comparing $\mathrm{CABG}$ alone and $\mathrm{CABG}$ plus ring for grade 2 FIMR. That study was recently followed by another multicenter study by Chan et al. ${ }^{9}$ In the study by Fattouch et $a{ }^{8}{ }^{8}$ a residual MR grade of only 0.8 after $\mathrm{CABG}$ plus ring compared with 1.7 in the CABG group was observed at a mean follow-up of 32 months. Furthermore, the LV dimensions and NYHA class had also improved compared with CABG alone, although no difference in 5-year mortality was observed. ${ }^{8}$ The study by Chan et al, ${ }^{9}$ although aiming to measure the difference in peak oxygen consumption, LV remodeling, and MR severity, did not succeed in showing improved survival and found a worse postoperative course after repair in terms of transfusion, intubation time, and operative time. Despite very similar patient characteristics and operative

TABLE 6. Delta-MR grade comparisons between both groups

\begin{tabular}{|c|c|c|c|c|c|c|c|c|c|}
\hline \multirow[b]{2}{*}{ Group } & \multicolumn{3}{|c|}{ From OR to 3 mo $(\%)$} & \multicolumn{3}{|c|}{ From OR to $12 \mathrm{mo}(\%)$} & \multicolumn{3}{|c|}{ From 3 mo to 12 mo $(\%)$} \\
\hline & Worse & Unchanged & Better & Worse & Unchanged & Better & Worse & Unchanged & Better \\
\hline CABG & 11 & 22 & 67 & 8 & 15 & 77 & 14 & 57 & 29 \\
\hline CABG plus ring & 54 & 46 & 0 & 69 & 31 & 0 & 33 & 67 & 0 \\
\hline$P$ value & & .016 & & & .004 & & & .129 & \\
\hline
\end{tabular}

$O R$, Operating room; $C A B G$, coronary artery bypass grafting; ring, downsizing mitral ring annuloplasty. 
TABLE 7. Postoperative echocardiographic parameters adjusted for preoperative level and between group comparisons at 3 and 12 months

\begin{tabular}{|c|c|c|c|c|c|c|}
\hline \multirow[b]{2}{*}{ Variable } & \multicolumn{3}{|c|}{3 mo } & \multicolumn{3}{|c|}{$12 \mathrm{mo}$} \\
\hline & CABG $(n=14)$ & CABG plus ring $(n=14)$ & $P$ value & CABG $(n=14)$ & CABG plus ring $(n=13)$ & $P$ value \\
\hline$\overline{\mathrm{ERO}}\left(\mathrm{mm}^{2}\right)$ & $7 \pm 4$ & $4 \pm 4$ & .679 & $4 \pm 5$ & $9 \pm 6$ & .553 \\
\hline Jet area $\left(\mathrm{cm}^{2}\right)$ & $3.8 \pm 1.5$ & $3.5 \pm 1.4$ & .882 & $3.4 \pm 1.1$ & $3.1 \pm 1.1$ & .834 \\
\hline LA area $\left(\mathrm{cm}^{2}\right)$ & $23 \pm 2$ & $22 \pm 2$ & .673 & $18 \pm 3$ & $22 \pm 3$ & .397 \\
\hline Jet area/LA area $(\%)$ & $16 \pm 6$ & $15 \pm 6$ & .904 & $16 \pm 5$ & $164 \pm 6$ & .860 \\
\hline $\mathrm{RV}(\mathrm{mL})$ & $10 \pm 5$ & $10 \pm 5$ & .970 & $7 \pm 6$ & $11 \pm 7$ & .648 \\
\hline $\mathrm{RF}(\%)$ & $6.8 \pm 3.6$ & $8.1 \pm 3.3$ & .798 & $4.1 \pm 3.6$ & $9.0 \pm 4.5$ & .419 \\
\hline LVEDD (cm) & $5.3 \pm 0.2$ & $5.3 \pm 0.1$ & .855 & $5.3 \pm 0.1$ & $5.4 \pm 0.1$ & .503 \\
\hline $\operatorname{LVESD}(\mathrm{cm})$ & $3.5 \pm 0.2$ & $4.1 \pm 0.2$ & .081 & $3.7 \pm 0.2$ & $4.0 \pm 0.2$ & .475 \\
\hline LVEDV (ml) & $97 \pm 11$ & $111 \pm 9$ & .344 & $112 \pm 6$ & $110 \pm 6$ & .869 \\
\hline LVESV (ml) & $42 \pm 8$ & $55 \pm 7$ & .245 & $50 \pm 6$ & $58 \pm 6$ & .427 \\
\hline FS $(\%)$ & $33 \pm 4$ & $26 \pm 4$ & .315 & $30 \pm 4$ & $28 \pm 4$ & .660 \\
\hline LVEF (\%) & $49 \pm 3$ & $42 \pm 2$ & .045 & $52 \pm 2$ & $48 \pm 2$ & .204 \\
\hline
\end{tabular}

$C A B G$, Coronary artery bypass grafting; ring, downsizing mitral ring annuloplasty; $E R O$, effective orifice area; $L A$, left atrium; $R V$, regurgitant volume; $R F$, regurgitant fraction; $L V E D D$, left ventricular end-diastolic diameter; $L V E S D$, left ventricular end-systolic diameter; $L V E D V$, left ventricular end-diastolic volume; $L V E S V$, left ventricular end-systolic volume; $F S$, fractional shortening; $L V E F$, left ventricular ejection fraction.

techniques, these results were not reproduced in the present study, in which we observed a lower residual MR grade in the CABG group and a higher residual MR grade in the $\mathrm{CABG}$ plus ring group. No explanation is obvious why $\mathrm{CABG}$ was more efficient and CABG plus ring less efficient in our study at relieving MR. Although not part of the protocol, 6 of 16 patients randomized to the CABG group had undergone preoperative viability studies, with only 2 of these studies suggesting some inferior wall viability. The large-scale National Institutes of Health-Canadian Institutes of Health Research-sponsored randomized study underway in North America should shed additional light on this issue.

Before making final conclusions about whether to add mitral annuloplasty to $\mathrm{CABG}$, the technique should be performed rigorously. Recurrent MR does occur after CABG plus ring, even if only in a subgroup of patients prone to failure. The predictive values of mitral annuloplasty failure were suggested by Braun et $a{ }^{3},{ }^{3}$ who identified enlarged left ventricles $>65 \mathrm{~mm}$, Calafiore et $\mathrm{al}^{15}{ }^{15}$ who identified a coaptation depth $>10 \mathrm{~mm}$, and Magne et al, ${ }^{5}$ who identified a posterior leaflet angle of $\geq 45^{\circ}$ as cutoff values to opt for valve replacement instead of repair. However, a subvalvular approach to improve repair durability has been suggested as an alternative solution to preserve the native valve. A key factor in the pathogenesis of ischemic MR is papillary muscle displacement away from the anterior annulus, causing mitral leaflet tethering and type IIIb leaflet dysfunction. It is important to realize that downsized ring annuloplasty only addresses Carpentier type I valve dysfunction caused by annular dilatation but does not correct apical tethering and might, in fact, even further increase leaflet tethering. ${ }^{16,17}$ In an effort to address the papillary muscle displacement and correct Carpentier type IIIb dysfunction, Kron et $\mathrm{al}^{18}$ introduced papillary muscle relocation in 2002, and in 2009, Langer et $\mathrm{al}^{19}$ published a series of a modified papillary muscle relocation technique concomitantly with $\mathrm{CABG}$ plus ring, showing improved freedom from recurrent MR compared with historical controls. Whether this will also be realized in a randomized setting remains to be seen.

The small sample size of the present study could have limited our power to detect important changes for some of the clinical or echocardiographic findings. First, recruitment was very difficult $(\leq 50 \%$ of the identified patients refused participation in the study). The present study was, in fact, terminated when the Montreal Heart Institute joined the National Institutes of Health-Canadian Institutes of Health Research project on moderate MR (CABG versus CABG with downsized ring annuloplasty). Those considerations taken into account, addressing moderate FIMR with CABG alone seems to be a simpler procedure with equally good clinical and echocardiographic improvement at 1 year.

\section{References}

1. Grigioni F, Enriquez-Sarano M, Zehr KJ, Bailey KR, Tajik AJ. Ischemic mitral regurgitation: long-term outcome and prognostic implications with quantitative Doppler assessment. Circulation. 2001;103:1759-64.

2. Aklog L, Filsoufi F, Flores KQ, Chen RH, Cohn LH, Nathan NS, et al. Does coronary artery bypass grafting alone correct moderate ischemic mitral regurgitation? Circulation. 2001;104(12 suppl 1):I68-75.

3. Braun J, van der Veire NR, Klautz RJ, Versteegh MI, Holman ER, Westenberg JJ, et al. Restrictive mitral annuloplasty cures ischemic mitral regurgitation and heart failure. Ann Thorac Surg. 2008;85:430-6.

4. Grossi EA, Woo YJ, Patel N, Goldberg JD, Schwartz CF, Subramanian VA, et al. Outcomes of coronary artery bypass grafting and reduction annuloplasty for functional ischemic mitral regurgitation: a prospective multicenter study (Randomized Evaluation of a Surgical Treatment for Off-Pump Repair of the Mitral Valve). J Thorac Cardiovasc Surg. 2011;141:91-7.

5. Magne J, Senechal M, Dumesnil JG, Pibarot P. Ischemic mitral regurgitation: a complex multifaceted disease. Cardiology. 2009;112:244-59.

6. Hung J, Papakostas L, Tahta SA, Hardy BG, Bollen BA, Duran CM, et al. Mechanism of recurrent ischemic mitral regurgitation after annuloplasty: continued LV remodeling as a moving target. Circulation. 2004;110(11 suppl 1):II85-90.

7. Benedetto U, Melina G, Roscitano A, Fiorani B, Capuano F, Sclafani G, et al. Does combined mitral valve surgery improve survival when compared to revascularization alone in patients with ischemic mitral regurgitation? A metaanalysis on 2479 patients. J Cardiovasc Med (Hagerstown). 2009;10:109-14. 
8. Fattouch K, Guccione F, Sampognaro R, Panzarella G, Corrado E, Navarra E, et al. POINT: efficacy of adding mitral valve restrictive annuloplasty to coronary artery bypass grafting in patients with moderate ischemic mitral valve regurgitation: a randomized trial. J Thorac Cardiovasc Surg. 2009;138:278-85.

9. Chan KM, Punjabi PP, Flather M, Wage R, Symmonds K, Roussin I, et al., RIME Investigators. Coronary artery bypass surgery with or without mitral valve annuloplasty in moderate functional ischemic mitral regurgitation: final results of the Randomized Ischemic Mitral Evaluation (RIME) trial. Circulation. 2012;126:2502-10

10. Carpentier A. Cardiac valve surgery-the "French correction" J Thorac Cardiovasc Surg. 1983;86:323-37.

11. Prifti E, Bonacchi M, Frati G, Giunti IG, Leacche M, Proietti P, et al. Should mild-to-moderate and moderate ischemic mitral regurgitation be corrected in patients with impaired left ventricular function undergoing simultaneous coronary revascularization? J Card Surg. 2001;16:473-83.

12. Rector TS, Cohn JN. Assessment of patient outcome with the Minnesota Living with Heart Failure questionnaire: reliability and validity during a randomized, double-blind, placebo-controlled trial of pimobendan. Pimobendan Multicenter Research Group. Am Heart J. 1992;124:1017-25.

13. Briançon S, Alla F, Méjat E, Guillemin F, Villemot JP, Mertes PM, et al. Measurement of functional inability and quality of life in cardiac failure: transcultural adaptation and validation of the Goldman, Minnesota and Duke questionnaires Arch Mal Coeur Vaiss. 1997;90:1577-85.

14. Gaasch WH, Zile MR. Left ventricular function after surgical correction of chronic mitral regurgitation. Eur Heart J. 1991;12(suppl B):48-51.

15. Calafiore AM, Di Mauro M, Gallina S, Di Giammarco G, Iaco AL, Teodori G, et al. Mitral valve surgery for chronic ischemic mitral regurgitation. Ann Thorac Surg. 2004;77:1989-97.

16. Zhu F, Otsuji Y, Yotsumoto G, Yuasa T, Ueno T, Yu B, et al. Mechanism of persistent ischemic mitral regurgitation after annuloplasty: importance of augmented posterior mitral leaflet tethering. Circulation. 2005;112(9 suppl): I396-401.

17. Gelsomino S, Lorusso R, De Cicco G, Capecchi I, Rostagno C, Caciolli S, et al Five-year echocardiographic results of combined undersized mitral ring annuloplasty and coronary artery bypass grafting for chronic ischaemic mitral regurgitation. Eur Heart J. 2008;29:231-40.

18. Kron IL, Green GR, Cope JT. Surgical relocation of the posterior papillary muscle in chronic ischemic mitral regurgitation. Ann Thorac Surg. 2002;74 600-1.

19. Langer F, Kunihara T, Hell K, Schramm R, Schmidt KI, Aicher D, et al. RING+STRING: successful repair technique for ischemic mitral regurgitation with severe leaflet tethering. Circulation. 2009;120(11 suppl):S85-91. 